\title{
Efficacy of Priming: Evidence from Expert Performance
}

\author{
Igor Bitensky1, Yaniv Mama², Daniel Algom ${ }^{1}$ \\ ${ }^{1}$ Tel-Aviv University, Tel Aviv, Israel \\ ${ }^{2}$ Ariel University, Ariel, Israel \\ Email: igorbitensky@yahoo.com
}

Received 5 September 2014; revised 2 October 2014; accepted 26 October 2014

Copyright (C) 2014 by authors and Scientific Research Publishing Inc.

This work is licensed under the Creative Commons Attribution International License (CC BY). http://creativecommons.org/licenses/by/4.0/

(c) (i) Open Access

\begin{abstract}
The vast majority of studies performed on the priming of attitudes, dispositions, and behavior engaged non-selective group of students as participants. This study engaged highly skilled experts as well as student cohorts. In a series of 3 experiments, professional chess players as well as non-selected groups of students were primed for risk-taking behavior. The priming manipulations included words (Experiments 1-2) and pictures (Experiment 3). The results showed that priming was roughly effective to the same extent with experts and non-experts. We conclude that experts are not immune of the influence of priming-their high motivation and domain-specific performance notwithstanding.
\end{abstract}

\section{Keywords}

Priming, Experts, Chess, Risk-Taking

\section{Introduction}

Much pertinent research in the domain of priming is sustained by the notion of unconscious motivation and action [see (Forster \& Liberman, 2007) for review]. This notion, of course, is an old one, widely popularized by the work of Sigmund Freud (e.g., 1901, 1920). However, for all its rich ramifications, the old unconscious has proved difficult to capture in a rigorous fashion. In contrast, the new unconscious unraveled within social cognition is grounded in functional contexts and is tractable experimentally. The new unconscious nonetheless shares two important assumptions with the old one. First, the causal sources of a person's behavior often occur outside of the person's intention or awareness. Second, these causal effects exhibit themselves in an automatic fashion. Taking advantage of the empirical verifiability of the new unconscious, our goal in this study was to test for its limits, namely, the conditions under which priming effects might no longer observed. 
In the typical priming study, the relevant mental substrate is activated in an unobtrusive manner and the automatic expressions of this activation are then tested in a subsequent phase. Employing this methodology, a wide variety of behaviors has been activated without the person's intent, spanning the gamut from rude action (Bargh et al., 1996) to walking speed (Bargh et al., 1996) to aggression (Mussweiler \& Forster, 2000) to competitiveness (Kay et al., 2004) to political behavior (Hassin et al. 2007) to social warmth (Bargh \& Shalev, 2011) or to risk taking (Erb et al., 2002). Despite the impressive demonstration of the power of priming, existing research is limited in one important aspect.

The majority of existing studies tested fairly routine behaviors such as walking, playing games, solving puzzles, or filling out questionnaires. Expert performance entailing mastery of (uncommon) skills has rarely been tested. It is moot whether the influence of priming reaches beyond everyday attitudes and behaviors onto the realm of highly practiced skilled behavior.

The goal of the present study was to probe the boundaries of priming through the assessment of its influence (or lack thereof) on expert performance. For expert performance, we tested chess moves by professional players. For unconscious activation, we primed risk taking on the board.

\section{Unconscious Automatic Activation of Risk Taking}

The idea of priming risk-taking seems puzzling at first glance. In order to be effective, risk-taking should be deployed in an adept manner. Deployment should be sensitive to changes in the environment (mainly to the moves by the opponent) and also to changes the person's own mental resources. Risk-taking must be flexible in order to achieve the desired future state (winning the game), whether consciously or unconsciously. However, as we also recounted, primed action is also unconscious and automatic. Can risk-taking be flexible and automatic at the same time? Notably, Hassin et al. (2009) have shown that automatic goal pursuit can be flexible without necessary mandating conscious control. Risk-taking can be considered thus as an extreme form of unconscious automatic goal pursuit.

People often take risky choices in order to achieve an important goal. In the research by Erb et al. (2002), the initial task for the participants was judging the frequency of occurrence of words in the language. Two groups were presented each with a set of 15 words. Interspersed within each set were 8 experimental words associated with risk. In the "risk-taking" group, 4 of the 8 experimental words had positive connotations with risk-seeking and 4 had negative connotations with risk-avoidance. In the "risk-avoidance" group, 4 of the 8 experimental words had negative connotations with risk-seeking and 4 had positive connotations with risk-avoidance. These unobtrusive manipulations presumably activated the respective mental states (without awareness) of the participants. In the second task, meant to observe any effects of the activated mental states, the participants indicated their preference for risky versus safe options with respect to brief stories entailing various scenarios. Predictably enough, the participants subjected to priming of risk-taking exhibited a preponderance of risky choices, whereas those in the "risk-avoidance" group gravitated toward taking the safe options. In the present study, we took advantage of the methods of Erb et al. to prime risk taking and risk avoidance by expert chess players. Are experts prone to priming?

\section{Expert Performance}

Despite its importance in theory and practice alike, a consensual definition of the concept of expert within social cognition does not exist. Paraphrasing William James on attention, everyone knows who an expert is. The problem is pinpointing those properties that make a person one. The following tautology illustrates the theoretical difficulty: "An expert is someone who carries out a specified set of tasks expertly" (Weiss \& Shanteau, 2003: p. 104). Espousing James, everyone knows the expert when she or he needs one-from the star surgeon to the experienced pilot to the judge of Olympic gymnastics. For some of these tasks, no measurable standard exists. One cannot be fully confident that the judges in the gymnastic contest accurately selected the most artistically valuable performer.

Ignoring theory for the moment, some features of expertise enjoy a fairly wide empirical support (Gobet \& Simon, 1996; Gobet \& Campitelli, 2007; Weiss \& Shanteau, 2003). First, expertise is domain specific. Chess champions do not appear to exhibit extraordinary performance in various cognitive areas apart from their genius in chess (Chase \& Simon, 1973). Second, the relevant skills are so well-practiced that expert performance often becomes automatic (Shiffrin \& Shneider, 1977). Third, commensurate with the previous characteristics, experts 
are often better than novices at ignoring task-irrelevant information (Shanteau, 1992). Fourth, experts make use of efficient thinking strategies to attain superior performance (Shanteau, 1992).

Again, for all the outstanding problems of definition, identifying experts in natural settings does not pose too great a problem. Because expertise is domain specific, there are people who are considered by their peers to be the best on their tasks. Following Shanteau (1992: p. 255) an expert is identified by "consensual acclamation." In some fields of expertise, performance can be measured in an objective fashion and the experts are those individuals who surpass a good standard, which is a universally accepted outcome measure. Operational definition of experts is easier in those domains in which an internationally recognized scale of professional capability exist. Chess performance belongs to this category due to the international Elo rating list (Elo, 1978), which rank-orders professional players.

This short review already makes it clear that professional chess players comprise a well-defined group of experts. Chess is actually the best and most widely agreed upon example of expertise, the least controversial one in the entire literature (cf. de Groot \& Gobet, 1996). In the words of Simon \& Chase (1973), "Chess offers cognitive scientists an ideal task environment for the study of...skilled performance.” It is for this reason that we elected to examine chess decisions (risky versus safe) by professional chess players. Does standard priming procedure affect experts?

\section{Chess Cognition}

Expertise is readily demonstrated in the game of chess. In a classic research, de Groot (1946/1965) found that expert chess players identified the best moves during their first perception of the chess position. The fast recognition meant that grandmasters were able to focus on the key features of the position within a short time window and subsequently take advantage of their superior recognition process. de Groot (1946/1965) reported that a world champion enjoys a good understanding of the overall position after looking at it for $5 \mathrm{~s}$, whereas an amateur does so only after 15 min —an almost two-hundred-fold difference. In another classic study, Chase and Simon (1973) similarly found that chess experts reproduced chess positions faster and more accurately than did novices. We note though that the superior performance of experts applied to standard, structured chess positions, but not to bizarre or random ones (see also de Groot \& Gobet, 1996). This feature underscores the domain specificity and stimulus contingency of chess expertise.

Since these pioneer studies, chess experts have further been shown superior in visual span (Reingold et al. 2001) and perceptual organization (de Groot \& Gobet, 1996). Chess experts have also been tested on imagery (Saariluoma, 1991), on recognition processes (Gobet \& Simon, 1996), on intuition (Chassy \& Gobet, 2011), on the so called Einstellung Effect (Bilalić et al. 2010) as well as on further psychological aspects (see Gobet et al., 2004 for a review). The overall results did not challenge the domain specificity of chess expertise.

For risk taking itself, Gerdes and Gränsmark (2010) measured differences in risk-taking behavior between female and male chess players. The researchers analyzed data from 1.4 million chess games and found that women were more risk-averse than men. For priming, Kiesel et al. (2009) used masked priming of impoverished chess configurations (with a mere two pieces on the board) entailing a checking or a non-checking position. Subsequently, the same types of target positions were presented for speeded decision of checking or nonchecking configuration. The researchers found that chess experts responded faster when the prime and target positions were congruent (both checking and both non-checking) than when they were incongruent. Priming did not influence decisions by novice chess players.

\section{The Present Study}

Clearly, existing research on priming expert chess performance is very limited. The aforementioned study by Kiesel et al. forms a valuable beginning, but it is moot whether their study truly tested expert decision making. The decision at question, whether or not the chess configuration is that of checking, is easily made by novices, too. The requested decision was made particularly easy by the fact that there was a single piece that was or was not threatening the king. Therefore, the decision tested in that study was hardly an expert decision. The priming itself was identity priming of a simple static situation. Risk taking, by contrast, offers examination of the full dynamics of behavior as it enfolds in time during the development of the game. As a result, this procedure enjoys ecological validity. This was done in the present study.

Risk-taking does not refer to simple actions such as grasping or walking, but rather to a wholesome disposi- 
tion to behave in a certain manner. It is for this reason perhaps that few studies attempted to prime risk taking. Given the paucity of attempts at priming this feature of behavior, our goal in Experiment 1 was to establish a reliable priming procedure for risk-taking based on that used by Erb et al. (2002). We note though that whereas Erb et al. tested attitudes, we wish to test actual risk-taking behavior.

Having primed risk-taking in Experiment 1, in Experiment 2 we proceeded using the same procedure to test risk-taking behavior on the chess board by professional chess players. Our goal was to test whether priming of risk-taking that impacted the behavior of student volunteers in Experiment 1 does the same with respect to expert behavior in Experiment 2. Our goal in Experiment 3 was to replicate and extend the findings of Experiment 2. The procedures used in Experiments 1-2 entailed words. In Experiment 3 we developed a procedure for priming risk taking with pictures. Successfully replicating experts priming with this new procedure would lend validation support for extending the efficacy of priming to a well-defined category of expertise. Therefore, chess players were primed to be risk-takers or risk-avoiders through prior exposure to pictures of famous masters known for their daring or conservative style.

We predicted that priming for risk taking can influence genuine behavior and not merely attitudes. Moreover, we predicted that it is possible to prime experts. Successful priming of non-experts (virtually all participants in existing research) but not of experts would indicate that priming is largely limited to persons and behaviors in a non-professional context.

\subsection{Experiment 1}

In order to test the hypothesis that risk taking can be primed, in this experiment we examined the behavior of non-expert participants. One group of participants was primed to be risk taking and another to be risk aversive. Following priming, the participants from both groups performed in a computer game with an opportunity to win real money. The participants had to take risky decisions in order to increase the monetary reward. Our dependent variable was the actual money accumulated or the point at which the participant decided to quit the game.

\subsubsection{Method}

\section{1) Participants}

Thirty-six (30 female, 6 male) Tel Aviv University undergraduate students participated in the study. They volunteered to take part in the experiment in partial fulfillment of course requirements. The average age of participants was 23.15 years $(\mathrm{SD}=1.38$ ). Twenty participants were primed for risk-avoidance and sixteen for risktaking.

\section{2) Stimuli and Apparatus}

Priming: We prepared 23 white cards $(6 \times 4 \mathrm{~cm})$ with a (Hebrew) word printed on each. The words were black (font David, size 36) and appeared in the center of the card. In the risk-seeking condition, the words included four adjectives with a positive connotation for risk-taking (brave, enterprising, daring, adventurous), four adjectives with a negative connotations for risk-avoidance (anxious, worried, timid, hesitant), and seven adjectives as distractors (polite, orderly, colorful, deceitful, naive, lovely, insult). In the risk-avoidance condition, adjectives with a negative connotation for risk-taking and a positive connotation for risk-avoidance replaced those from the first condition. The adjectives with a negative connotation for risk-seeking were hasty, rash, impulsive, and risky. The adjectives with a positive connotation for risk-avoidance were conscientious, responsible, careful and reasonable. The same distractor adjectives were used for this group, too. Our manipulation of priming followed that used by Erb et al. (2002).

Risk-taking in a computer game: We composed a computer game in which the participant was required to make a simple response (pressing a key) to gain money. There was not any particular stimulus involved (or presented), hence the response was not selective and required no skills. The task was a simple "gamble" to gain as much money as possible. Each response carried the gain of 0.5 Israeli Shekel (IS). The participant could stop responding at any point, exit the game, and leave the experiment with the accumulated sum at hand. Notably, the game sequence could also stop unpredictably (from the participant's point of view) in which case the terminated participant lost all her or his money. In point of fact, termination was not random, but occurred at the point at which 18.50 IS was earned.

The participant was instructed to press the A key for getting 0.5 IS each time and was informed that she or he could leave the game at any time with the money at hand. However, the participant was also informed that a 
“termination” sign appearing in a random fashion would mean the end of the game losing all the money earned.

Stimulus presentation and measurement were governed by a DirectRT Precision Timing Software (Version 2008.1.0.11). The stimuli were displayed on a 17 in. color monitor set to a resolution of $1024 \times 768$ pixels.

\section{3) Procedure}

On arrival to the laboratory, the participants were told that they would take part in an experiment composed of two tasks. They were assigned to either the risk-taking or the risk-avoidance priming group. In the first task, the participants in each group were asked to rank order the frequency of occurrence in everyday speech of fifteen words. The cards with the words were placed on a desk in front of the participant. The participants evaluated the frequency of the words by sorting the cards and then writing down the words from the most frequent to the least frequent. After exposure to the list of words (a different list for the two groups), all participants engaged in the computer game. The game consisted of pressing a key in order to get the sum of 0.5 IS for each key press. In the game, the participant had to decide between two options at each step. The participant could decide to leave the game with the money earned up to that point, or decide to continue playing at the risk of losing it all. At the end of the experiment, the participants (who earned money) received the money they won. Debriefing at the end of the experiment indicated that none of the participants was aware of the true nature of the study.

\subsubsection{Results and Discussion}

The priming of risk-taking or lack thereof made a difference in the tendency to continue playing in the face of risking one's money. Of the 16 participants who had been primed to be risk-takers, half were terminated (and lost their earnings). By contrast, only 4 of the 20 participants who had been primed to be risk-aversive were so terminated (see Figure 1). In other words, the great majority of the participants in the risk-avoidance group preferred not to take risks and leave the game earlier, before possible termination. This difference in behavior between the two groups amounted to a reliable effect of priming $\left[\chi^{2}(1)=7.2, p<0.05\right]$. Considering the actual amount earned by all non-terminated participants, those in the risk-taking group still outperformed those in the risk-avoidance group, although this difference was not reliable (means of 13.2 and 12.1 IS, respectively). Finally, considering the money "earned" by terminated participants to be 18.5 IS (thereby including all the participants in the analysis) again yielded a reliable difference favoring the risk-taking group [means of 15.9 and 13.4 IS; $t$ (34) $=1.88, p<0.05]$.

The upshot is, priming can influence actual risk taking behavior. The participants who were primed by a riskavoidance procedure quit the game at an earlier stage than did participants who were primed by a risk-seeking procedure.

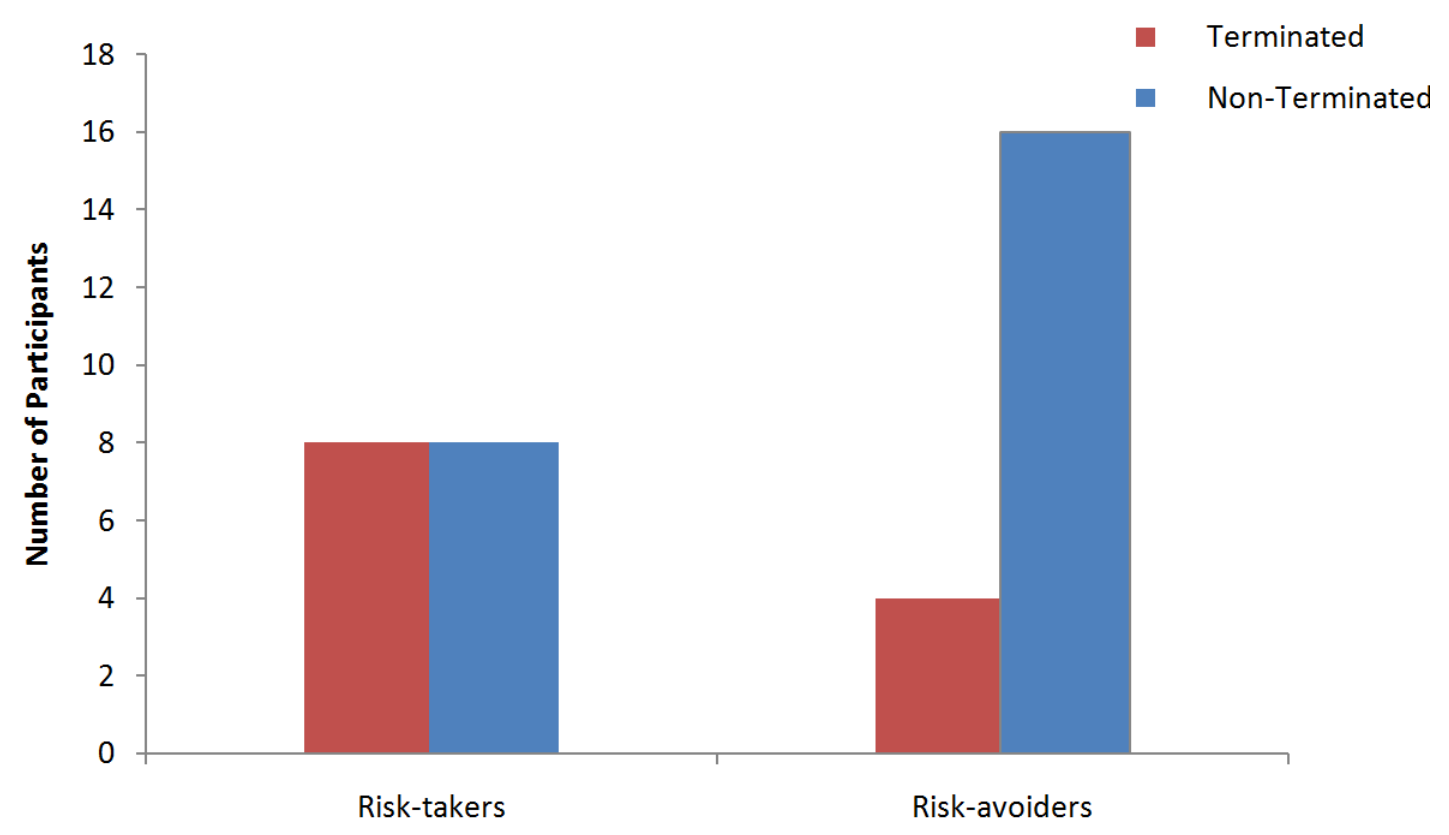

Figure 1. Number of terminated and non-terminated participants in two groups (risk-taking vs. risk-avoidance). 


\subsection{Experiment 2}

Risk taking can be reliably primed when the task does not require high skills and the data come from the general (student) population. Can the same procedure influence skilled behavior by experts? In order to test this question, the participants in Experiment 2 were experienced chess players. The priming procedure was that used in Experiment 1 , but risk taking was observed by a decision within the game of chess. Would a player who had been primed to take risk choose a more risky move on the board than a player who had been primed to be risk-aversive?

\subsubsection{Method}

\section{1) Participants}

Seventeen (1 female, 16 male) chess players participated in the study. They were recruited via advertising in chess clubs in a greater Tel-Aviv area. They participated on a voluntary basis. The average age of participants was 27.4 years $(\mathrm{SD}=2.47)$. All the participants have been competing in professional tournaments for at least five years. Their average Elo rating was 2164 points. The players were randomly assigned to either the risk taking $(\mathrm{N}=9)$ or the risk avoidance $(\mathrm{N}=8)$ condition.

\section{2) Stimuli and Apparatus}

The manipulation of priming was the same as that used in Experiment 1. The task was created by using standard sets of chess pieces and chess clocks. The stimulus chess position was drawn from the game Glek, I.--Malishauskas, V. (Tallinn, 1986) (see Figure 2).

The participants were asked to consider the situation presented on the board, assuming that they are playing with the white pieces. Moreover, they were told that it was their turn to move next. The participants were given five minutes to examine the position and complete their move.

Most important, the task invited a binary decision between two possible moves. One move $(\mathrm{Rf} 1 \times \mathrm{f6})$ involves a sacrifice of the rook for a bishop, a risky option. The other move (Kc3-d5) is conservative, a safe option. An informal query of players from chess clubs showed that (without priming) the two options are chosen approximately equally. Note also that the position had no "correct" solution, and that both options were equally valuable in terms of chess.

\section{3) Procedure}

The experiment took place in two chess clubs, one in Tel-Aviv and the other in Petach Tikva. The participants were told that they would take part in a decision making experiment composed of two parts. The first task was a linguistic task and the second a chess task. The priming procedure was the same as that of Experiment 1 . After completing the word task, the participants were presented with the chess task, sitting at the white side of a chess board. At that point, the experimenter presented the two possible options for continuation and turned on the chess clock. Making the decision, the participant moved the chess piece on the board and pressed the clock. The experimenter recorded the move and the time it took to make it. The debriefing indicated that no participant realized the true nature of the study.

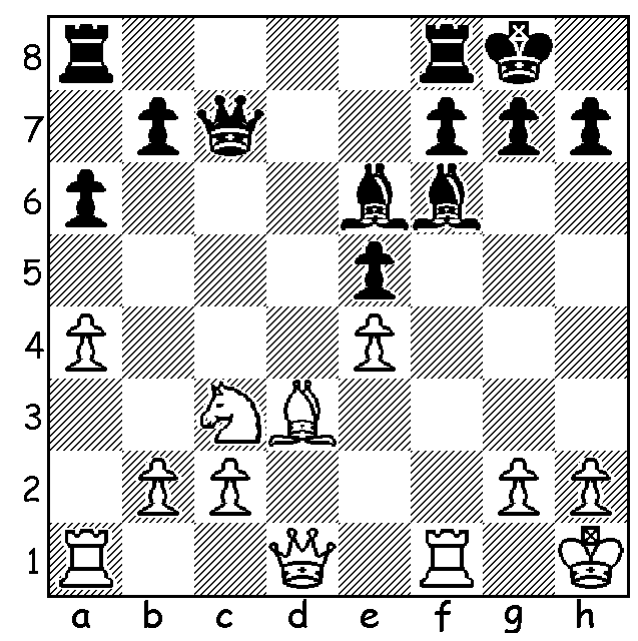

Figure 2. Stimulus chess position (white to move). 


\subsubsection{Results and Discussion}

The respective priming procedures—risk-taking or risk-avoidance-influenced subsequent behavior in a commensurate fashion. The majority of the participants who had been primed to be risk-takers selected the risky move on the chess board (7 and 2, respectively, for risky and safe moves). The binary choice reversed for players who were primed to avoid risk (3 and 5, respectively, for risky and safe moves, Figure 3). Statistical analysis confirmed the influence of priming risk-taking on the board $\left[\chi^{2}(1)=2.83, p<0.05\right]$.

Concerning latency, the participants in the risk-taking group spent on their decision $3.02 \mathrm{~min}$., on average, whereas the participants in the risk-avoidance group did so $3.57 \mathrm{~min}$., on average. This difference was not reliable, $\mathrm{t}(15)=-0.76, p>0.05$. Ignoring for the moment group membership, we contrasted the data for risky and safe decisions on the board. The participants who took the risky move spent significantly less time on their decision than the participants who took the safe move [2.75 and $3.54 \mathrm{~min}$.), $\mathrm{t}(14)=-1.95, p<0.05]$.

This experiment pioneered to show that priming of risk taking exerts influence on actions by experts, too. Chess players who were primed to take risk did subsequently select a risky move on the board more often than did players who were primed to avoid risk.

In the next experiment, we again primed expert chess players, but used a different priming procedure. The goal of this experiment was to provide cross validation support to the results of Experiment 2 with a brief nonverbal priming.

\subsection{Experiment 3}

Experiment 3 was a conceptual replication of Experiment 2. We used a new priming procedure entailing exposure to relevant pictures (cf. Shantz \& Latham, 2009).

\subsubsection{Method}

\section{1) Participants}

Twenty two (male) chess players participated in the study. They were recruited via advertising in chess clubs. They participated on a voluntary basis. The average age of participants was 28.7 years (SD $=12.5)$. All the participants have been competing in professional tournaments for at least five years. Their average Elo rating was 2104 points. The players were randomly assigned to either the risk taking $(\mathrm{N}=12)$ or the risk avoidance $(\mathrm{N}=10)$ condition.

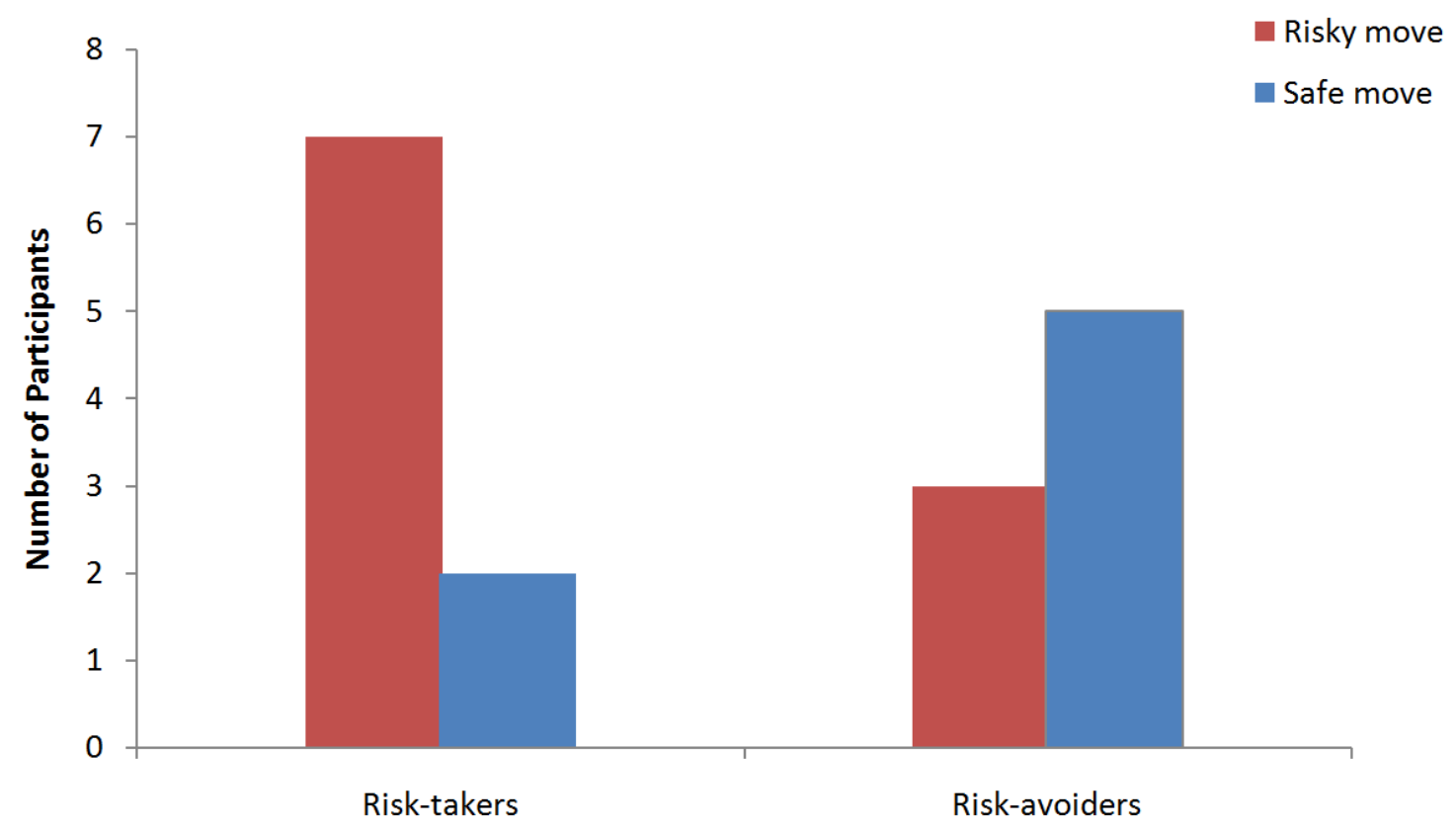

Figure 3. Number of participants who chose risky or safe move as function of the priming procedure (risk-taking vs. risk-avoidance). 


\section{2) Stimuli and Apparatus}

A new (two-page) questionnaire was prepared. The first page contained 4 questions of biographic nature. There were two versions of the second page. In the first version, the pictures of the following famous masters appeared on the top with their names presented in a different random order at the bottom: Boris Spassky, Nigel Short, Mikhail Tal, and Alexei Shirov. The last two masters are highly associated with risk. In the second version, comparable in preparation to the first, the masters were: Boris Spassky, Nigel Short, Mikhail Botvinnik, and Vladimir Kramnik. The last two masters are highly associated with conservative positional play. The first two masters in both questionnaires are neither habitual risk-takers nor habitual risk-avoiders; they are known for their universal style.

Priming: The participants in the risk-taking group were presented with the first version including masters Mikhail Tal and Alexei Shirov. The task was to identify all masters by drawing appropriate lines connecting the pictures and the names. The participants in the risk-avoidance group were presented with the second version including masters Mikhail Botvinnik and Vladimir Kramnik. The task was the same as in the first group, namely connecting pictures and names by lines.

Test of risk taking: The subsequent chess task was the same as that used in Experiment 2.

\section{3) Procedure}

The experiment took place in chess clubs in Tel-Aviv, Jerusalem, Rishon-Letzion, and Ramat-Gan. The participants first completed the 2-page questionnaire. After providing some biographical details, they identified four famous masters by associating their pictures with their respective names. At this point, the participants were presented with the chess task of Experiment 2, sitting at the white side of the board. All details of the task and the recording of the responses were the same as those in Experiment 2. The debriefing indicated that no participant realized the true nature of the study.

\subsubsection{Results and Discussion}

The majority of the participants who had primed to be risk-takers selected the risky move on the chess board (10 and 2, respectively, for risky and safe moves). The pattern of choice changed for players who were primed to avoid risk (5 and 5, respectively, for risky and safe moves, Figure 4). Statistical analysis confirmed the influence of priming by pictures on risk-taking on the board $\left[\chi^{2}(1)=2.79, p<0.05\right]$. The latency to decision did not differ across groups or the individual participants.

The current results are important in showing the potency of priming risk taking by mere presentation of appropriate pictures (and names). One should recall that, in the world of chess, individual styles of masters are

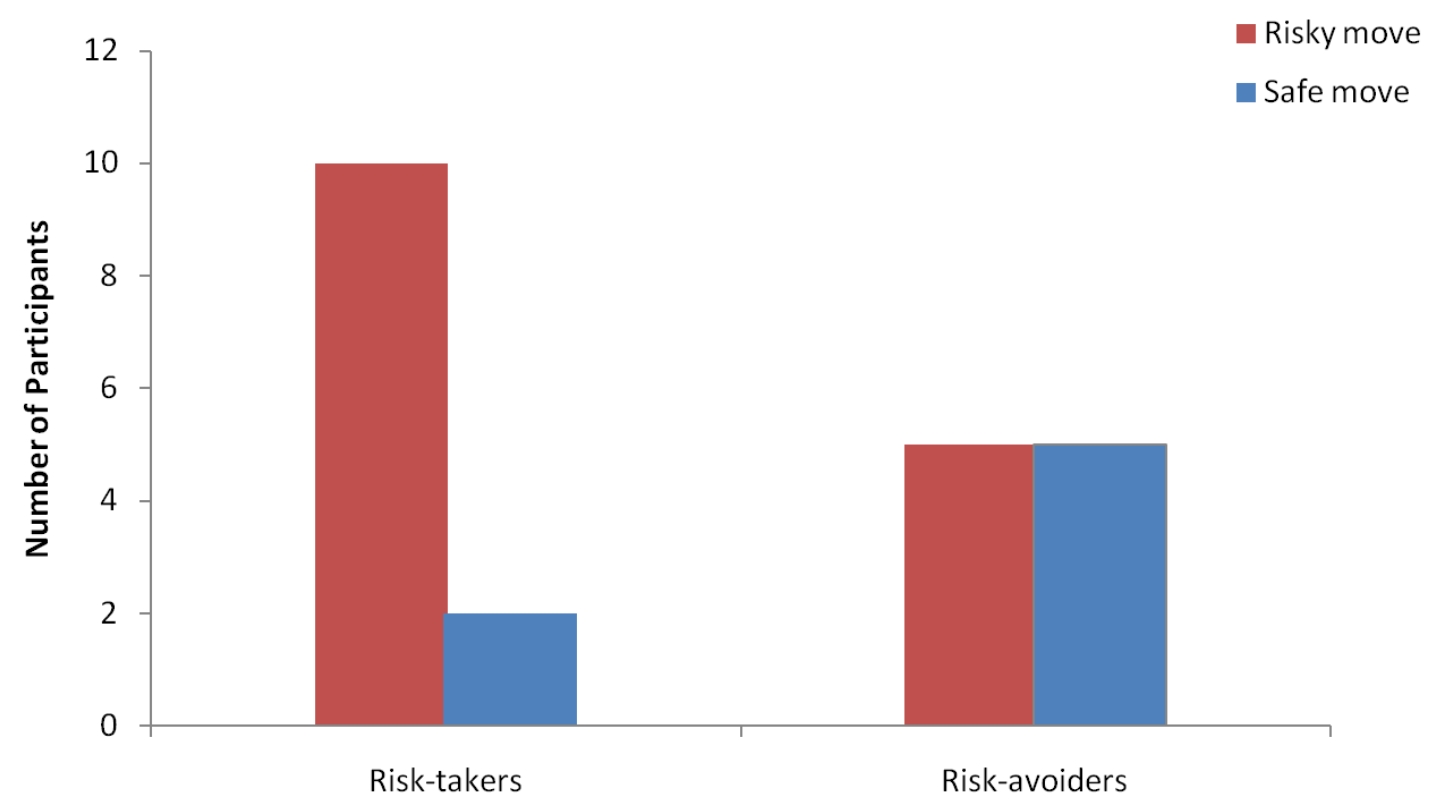

Figure 4. Number of participants who chose risky or safe move as function of the priming procedure (risk-taking vs. risk-avoidance). 
very well known. These particular styles serve as inspiration for thousands of players around the world, who strive to emulate them. This might explain the efficiency of unconscious priming by exposure to pictures of masters. The results of Experiment 3 provide further support for the feasibility of 1) priming risk-taking, and of 2) the efficacy of priming this feature with experts.

\section{Conclusion}

The goal of this study was to explore some boundaries of the priming phenomenon. Does priming exert an influence on expert behavior? Conceivably, sustained training and specialization in a given field can make it immune to such effects. Too, experts are typically motivated to succeed in their field of expertise, a level of motivation not usually present with the student populations tested in a great bulk of existing research. The expert groups under test included professional chess players. Given their high motivation to succeed, it was not clear that priming would work with their highly skilled performance.

We addressed these issues in a series of 3 experiments. First, we established the efficacy of priming to affect subsequent risk-taking behavior in the general (student) population. Second, we showed that experts are sensitive to priming. Players primed to be risk-takers selected adventurous moves on the board more often than did players primed to be risk-averts. This effect on risk-taking was obtained by different means of priming (verbal and pictorial). This first foray into the domain of priming expert performance already showed promising results with respect to the wide reach of the priming procedure. More research is needed to replicate and extend these data.

\section{References}

Bargh, J. A., Chen, M., \& Burrows, L. (1996). Automaticity of Social Behavior: Direct Effects of Trait Construct and Stereotype Priming on Action. Journal of Personality and Social Psychology, 71, 230-244 http://dx.doi.org/10.1037/0022-3514.71.2.230

Bargh, J. A., \& Shalev, I. (2011). The Substitutability of Physical and Social Warmth in Daily Life. Emotion, 12, $154-162$. http://dx.doi.org/10.1037/a0023527

Bilalić, M., McLeod, P., \& Gobet, F. (2010). Inflexibility of Experts-Reality or Myth? Quantifying the Einstellung Effect in Chess Masters. Cognitive Psychology, 56, 73-102. http://dx.doi.org/10.1016/j.cogpsych.2007.02.001

Chase, W. G., \& Simon, H. A. (1973). Perception in Chess. Cognitive Psychology, 4, 55-81. http://dx.doi.org/10.1016/0010-0285(73)90004-2

Chassy, P. \& Gobet, F. (2011). A Hypothesis about the Biological Basis of Expert Intuition. Review of General Psychology, 15, 198-212. http://dx.doi.org/10.1037/a0023958

de Groot, A. (1946). Het denken van den Schaker. Amsterdam: Noord Hollandsche

de Groot, A. (1965). Thought and Choice in Chess (2nd ed.). The Hague: Mouton Publishers.

de Groot, A. \& Gobet, F. (1996). Perception and Memory in Chess. Heuristics of the Professional Eye. Assen: Van Gorcum.

Elo, A. (1978). The Rating of Chessplayers, Past and Present. New York: Arco.

Erb, H. P., Bioy, A., \& Hilton, D. J. (2002). Choice Preferences without Inferences: Subconscious Priming of Risk Attitudes. Journal of Behavioral Decision Making, 5, 250-258. http://dx.doi.org/10.1002/bdm.416

Forster, J., \& Liberman, N. (2007). Knowledge Activation. In A. Kruglanski, \& Higgins, E. T. (Eds.), Social Psychology: Handbook of Basic Principles (2nd ed., pp. 201-231). New York: Guilford Press.

Freud, S. (1901). The Psychopathology of Everyday Life: Forgetting, Slips of the Tongue, Bungled Actions, Superstitions and Errors. London: Ernest Benn Limited.

Freud, S. (1920). A General Introduction to Psychoanalysis. New York: Horace Liveright. http://dx.doi.org/10.1037/10667-000

Gerdes, C., \& Gränsmark, P. (2010). Strategic Behavior across Gender: A Comparison of Female and Male Expert Chess Players. Labour Economics, 17, 766-775. http://dx.doi.org/10.1016/j.labeco.2010.04.013

Gobet, F., \& Simon, H. A. (1996). The Roles of Recognition Processes and Look ahead Search in Time-Constrained Expert Problem Solving: Evidence from Grandmaster Level Chess. Psychological Science, 7, 52-55. http://dx.doi.org/10.1111/j.1467-9280.1996.tb00666.x

Gobet, F., de Voogt, A., \& Retschitzki, J. (2004). Moves in Mind: The Psychology of Board Games. Hove: Psychology Press.

Gobet, F., \& Campitelli, G. (2007). The Role of Domain-Specific Practice, Handedness and Starting Age in Chess. Deve- 
lopmental Psychology, 43, 159-172. http://dx.doi.org/10.1037/0012-1649.43.1.159

Hassin, R. R., Ferguson, M. J., Shidlovsky, D., \& Gross, T. (2007). Subliminal Exposure to National Flags Affects Political Thought and Behavior. Proceedings of the National Academy of Sciences, 104, 19757-19761. http://dx.doi.org/10.1073/pnas.0704679104

Hassin, R. R., Bargh, J. A., \& Zimerman, S. (2009). Automatic and Flexible: The Case of Nonconscious Goal Pursuit. Social Cognition, 27, 20-36. http://dx.doi.org/10.1521/soco.2009.27.1.20

Kay, A. C., Wheeler, S. C., Bargh, J. A., \& Ross, L. (2004). Material Priming: The Influence of Mundane Physical Objects on Situational Construal and Competitive Behavioral Choice. Organizational Behavior and Human Decision Processes, 95, 83-96. http://dx.doi.org/10.1016/j.obhdp.2004.06.003

Kiesel, A., Kunde, W., Pohl, C., Berner, M. P., \& Hoffmann, J. (2009) Playing Chess Unconsciously. Journal of Experimental Psychology: Learning, Memory, and Cognition, 35, 292-298. http://dx.doi.org/10.1037/a0014499

Mussweiler, T., \& Förster, J. (2000). The Sex-Aggression Link: A Perception-Behavior Dissociation. Journal of Personality and Social Psychology, 79, 507-520. http://dx.doi.org/10.1037/0022-3514.79.4.507

Reingold, E. M., Charness, N., Pomplun, M., \& Stampe, D. M. (2001). Visual Span in Expert Chess Players: Evidence from Eye Movements. Psychological Science, 12, 49-56. http://dx.doi.org/10.1111/1467-9280.00309

Saariluoma, P. (1991). Aspects of Skilled Imagery in Blindfold Chess. Acta Psychologica, 77, 65-89. http://dx.doi.org/10.1016/0001-6918(91)90065-8

Shanteau, J. (1992). Competence in Experts: The Role of Task Characteristics. Organizational Behavior and Human Decision Processes, 53, 252-266. http://dx.doi.org/10.1016/0749-5978(92)90064-E

Shantz, A., \& Latham, G. P. (2009). An Exploratory Field Experiment of the Effect of Subconscious and Conscious Goals on Employee Performance. Organizational Behavior and Human Decision Processes, 109, 9-17. http://dx.doi.org/10.1016/j.obhdp.2009.01.001

Shiffrin, R. M., \& Schneider, W. (1977). Controlled and Automatic Human Information Processing. II. Perceptual Learning, Automatic Attending and a General Theory. Psychological Review, 84, 127-190. http://dx.doi.org/10.1037/0033-295X.84.2.127

Simon, H. A., \& Chase, W. G. (1973). Skill in Chess. American Scientist, 61, 394-403.

Weiss, D. J., \& Shanteau, J. (2003). Empirical Assessment of Expertise. Human Factors: The Journal of the Human Factors and Ergonomics Society, 45, 104-116. 
Scientific Research Publishing (SCIRP) is one of the largest Open Access journal publishers. It is currently publishing more than 200 open access, online, peer-reviewed journals covering a wide range of academic disciplines. SCIRP serves the worldwide academic communities and contributes to the progress and application of science with its publication.

Other selected journals from SCIRP are listed as below. Submit your manuscript to us via either submit@scirp.org or Online Submission Portal.
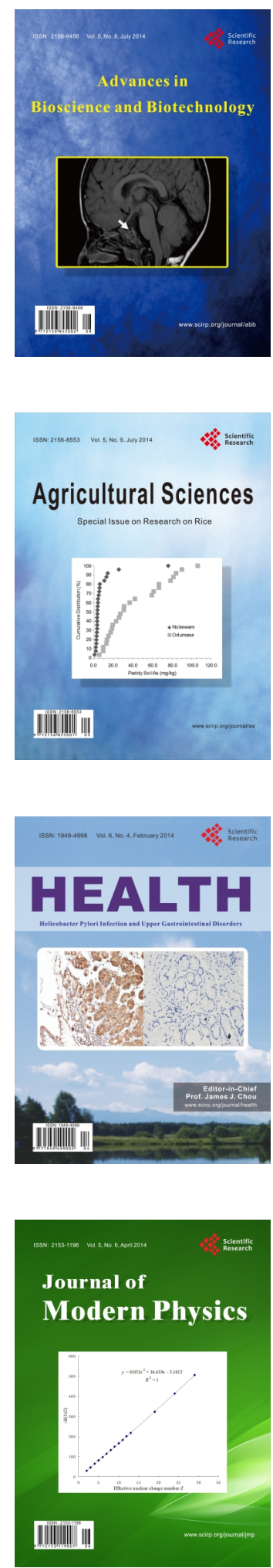
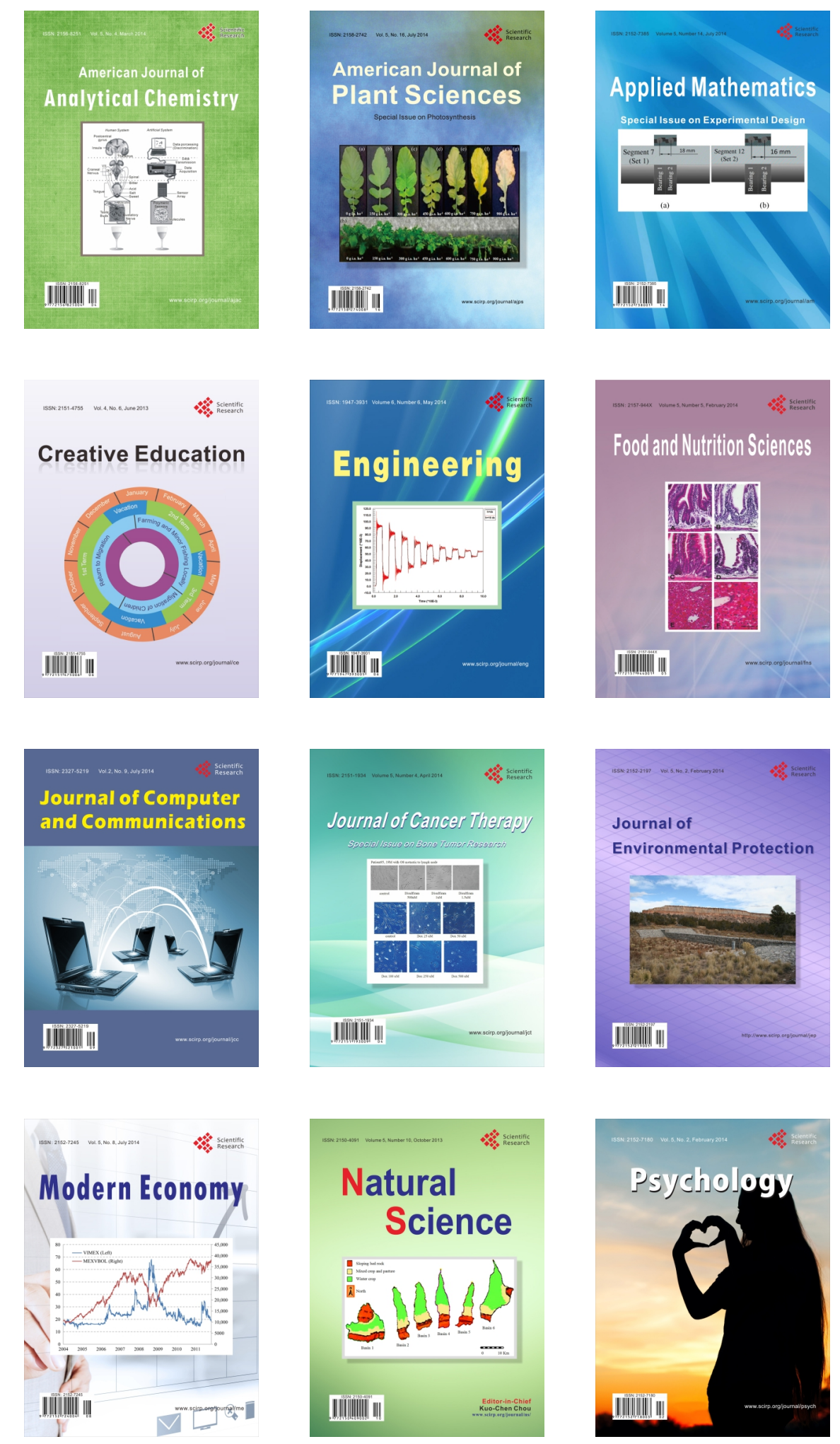